\title{
102
}

\section{Research and practice of CAI in Chinese basic education}

\author{
Li Shao Hui
}

National Research Centre of Computer Education

Beijing

China

He Ke Kang

Zhao Wei Hua

Beijing Normal University

China

\begin{abstract}
In this paper we first introduce the background of computer education in China, then we put emphasis on CAI (Computer Assisted Instruction) especially on CAI in elementary Chinese and mathematics which are the two most important subjects in basic education. We then present the project of 'four combinations' which has a significant influence on Chinese CAI and educational computer applications in China. We introduce three typical examples from elementary mathematics which have taken place in Guang Xi Zuang Autonomous Region, PingJiang Experimental School of SuZhou City and Beijing. We end the paper by drawing some conclusions about CAI in Chinese fundamental education and future developments.
\end{abstract}

Main conference themes: tutoring

Educational areas:

Study topics: languages, mathematics

Secondary keywords: courseware, computer assisted instruction, innovation, policy, research 


\section{INTRODUCTION}

Following the economic and information technology developments in China computer education has developed a great deal since 1982 and has gone into a deeper and new developmental phase in the 1990's. The State Education Commission (SEC) convened the fourth national computer education conference on basic education in 1991 and in 1992, and appointed SEC's vicepresident to be the leader of the national computer education group on basic education. In the same year the National Research Centre on Computer Education in Secondary Schools (NRCCE) which has certain administrative rights and is a research centre on computer education, changed its aim to primary and secondary education. Between 1992 and 1994 NRCCE drew up several documents on computer education such as the National Computer Education Plan (1994-2000), the Educational Software Development Plan (1994-2000), a Syllabus for Computer Courses, a Syllabus for Teacher Training for Computers, a Reference on Computer Hardware Selection, etc. These documents have been issued by SEC and act as guides to the development of computer education in Chinese basic education.

From the beginning computer education in China has developed from individual and scattered experiments towards systematic research and applications which have defined goals, plans and organization; from interesting out of class activities and optional computer courses to today's multilevel computer education system including computer courses within the school curriculum, computer based education (CBE or CAI) and computer managed education. Currently, to meet the challenge of the 21 st century's information society the Chinese basic education system is in a educational reform concerning ideas and instructional content, as well as teaching and learning methods. A new challenge is how to use modern computer media and combine these into educational processes so as to benefit from the combination. In this paper, we focus on primary school CAI, especially CAI in the two subjects of Chinese and mathematics, and in doing so reflect on the current situation and future developments of CAI in China.

\section{THE PROJECT OF 'FOUR COMBINATIONS'}

'Four combinations' means to combine CAI with Chinese teaching in primary school, that is, to combine Chinese literacy teaching, consulting a Chinese dictionary, coding Chinese characters and Chinese typing in the teaching process for learning Chinese. The project was approved by SEC in late 1993 and is managed by Prof. He Ke Kang. The goals of the project are to compile 
new textbooks which can make 'four combinations' a reality and to develop a series of courseware on Chinese character strokes, stroke order, Chinese character structure, character components, idiom, Chinese phonetic alphabet, Chinese pronunciation, etc. The project is important not only to Chinese language teaching and learning, but also has a significant influence on computer application and popularization in China. As everyone knows working and living without a computer is hard and almost unbelievable in a modern information society. Qualified citizens should be able to use a computer as easily as paper and pen. The degree of computer application and popularization in China is far behind the western countries; besides the limitations of economics and technological development an important reason is that input of Chinese characters into a computer is far more complex and difficult than input of alphabetic text.

Chinese is developed from a kind of hieroglyph and has a large set of characters; even the best Chinese character coding scheme needs thousands of characters and special training programs are needed to master it. To solve the problem of computer input there is only one way, that is combining elementary Chinese language teaching, Chinese coding training and Chinese typing with computer education - the 'four combinations'. Students should acquire basic knowledge - as well as the skills of inputting Chinese characters into a computer and typing skills-over the years of basic education. The combination is close and natural, for example, the Chinese character coding scheme can be taught simultaneously with the teaching of Chinese character strokes, stroke order, Chinese phonetic alphabet, character components, etc.

Student knowledge can be based on Chinese language knowledge, the Chinese character coding scheme and the rules of Chinese character separation, all combined naturally together. The knowledge and skills thus learned through basic education are not easily forgotten in one's later life. Typing Chinese characters into a computer could become as easy as using pen and paper if the 'four combinations' are established early in life, in this way solving the problem of computer application and popularization. To realize the 'four combinations' the key technological requirement is to design a Chinese Character Coding Scheme (CCCS) suitable to a student's knowledge structure and to Chinese language teaching laws and standards. CCCS represents Chinese characters with numbers or letters and codes every Chinese character according to strokes, stroke order and components of characters, and then allows input of the characters using a common ASCII keyboard.

Nowadays there are hundreds of CCCSs, but none was designed on the basis that the scheme should be adaptive to a student's knowledge structure and Chinese teaching laws and standards. To solve the problem Prof. $\mathrm{He} \mathrm{Ke}$ Kang invented a new CCCS named 'cognitive CCCS' which is suitable for the 
'four combinations' project. Cognitive CCCS is designed on the basis of the formation theory of Chinese characters and of theories from cognitive psychology concerning chunks in short-term memory; it also strictly upholds Chinese language teaching laws and standards. It was tested successfully in some primary schools in some provinces of China before publication and has gained high appraisal from experts. Cognitive CCCS is the latest achievement in the field of Chinese character information processing and will strongly promote the application and popularization of computers in China; it has therefore got broad attention within Chinese society. The 'four combinations' project is to develop a courseware series of Computer Assisted Chinese Language Learning (CACLL) and will compile new Chinese textbooks.

We have chosen several primary schools as experimental schools of 'four combinations' project in some provinces of China. The experiences and results will be disseminated after the completion of the experimental phase. It is impressive to see that the 'four combinations' experiment is not only practical, but also effective: it will dramatically change the traditional teacher centred teaching model and instructional methods, as well as educational thoughts and theories. It will encourage the reform of Chinese basic education to be more deep and wide.

\section{EXPERIMENTS WITH PRIMARY MATHEMATICS CAI}

Together with language instruction primary mathematics is one of the most important parts of basic education. Teaching primary mathematics helps children to develop a foundation of mathematics, to develop thinking abilities and an interest in mathematics learning, to develop good learning habits and it also helps to raise the quality of the whole nation. To explore CAI in primary mathematics instruction for improving learning methods and teaching quality many primary schools in some provinces, cities and autonomous regions of our country have for several years done experimental research with some successful outcomes. Representative and important examples are primary mathematics computer instruction in the Guang Xi Zhuang Autonomous Region and at PingJiang Experimental School in SuZhou. In order to solve the problems of courseware development for primary mathematics CAI and to go deeper into the problems a series of software developments and experimental research projects is being carried out by a cooperative research group. The members of the group are from NRCCE and the Institute of Modern Educational Technology (IMET) of Beijing Normal University. Below follow three typical examples which show the overall situation and characteristics of the experimental research on Chinese primary mathematics CAI. 


\section{Guang Xi Zhuang Autonomous Region}

The CAI experiment in primary schools of Guang Xi Zhuang Autonomous Region began in 1989. The first step of mathematics CAI was carried out in the Third Elementary School of LiuZhou and the fifth Elementary School of Railway in LiuZhou. According to the syllabus, the textbook and their personal teaching experiences the schools developed the instructional software on China Educational (8-bit) Computers. Some software helped teachers to tutor or illustrate; other software provided sufficient exercises in class and in review. This software is generally operated on the computer network of China Educational Computers. After some success the Education Committee of the Autonomous Region accepted the Primary Mathematics CAI Experiment project which was assigned by the Fundamental Education Department of SEC in 1991.

In 1992 the same experiments on primary mathematics CAI were done in ten other primary schools in the Autonomous Region. $30 \%$ of the pupils in the experimental schools had their mathematics lessons on microcomputers using the software mentioned. These experimental courses fully used features of the computers such as presenting a variety of information (including text, image, animation and sound), drill and practice, control, interaction, feedback, networking and so on. These also brought together the teaching experiences of excellent teachers and aroused pupils' learning interests, added more information within limited class time and cut down children's homework burden. The CAI in the network environment combined individualized teaching and learning with traditional class teaching. It was a useful attempt at exploring the measures and ways of introducing CAI into teaching and learning processes.

\section{PingJiang Experimental School in SuZhou}

The primary thinking of pupils is based on image thinking and then grows step by step to abstract thinking. During this process the principles of visualization and intuition are very important. Some concepts, important content or difficult points in mathematics can be understood by pupils only through observation, examples and animation. Computers are the best teaching tool for this while other means cannot meet the requirements. Therefore from 1990 PingJiang Experimental School in SuZhou developed a series of software on geometry for China Educational Computers according to the requirements of primary mathematics instruction and pupils' learning characteristics. All of this instructional software is used mainly to demonstrate or simulate in the teaching of geometry in primary mathematics. By means of the computer's dynamic imitation and movement of static shapes we can remedy defects in pupils' perceptive knowledge and spatial imagination; also defects in teachers' 
expression and illustration. In teaching geometry knowledge about shape, represented in static pictures, is gradually displayed by parallel movement, extending, stretching, rotating, flashing and so on. As a result pupils gain practical experience and receive a deep impression.

\section{Upgrading the computer systems}

With the development of computer technology and computer education in China, computer systems are upgrading rapidly from 8 bit computers like the China Educational Computer to 286 or 386 compatible PCs. The shortage of courseware to run on 286 or 386 computers is one of the main obstacles to the application of PC compatible computers in education. Moreover school teachers who want to use courseware, have to develop this by themselves or ask someone to develop CAI software according to their requirements. This work needs manpower and financial resources placing extra burdens on teachers and school administrators. Software developed spontaneously by schools or teachers is usually not easily interchangeable because of low quality, lack of ease of use or because the programs are based on an individual teacher's own style. CAI development will be impeded, if this situation is not changed.

The shortage of courseware and the rapid growth in numbers of 286 and 386 computers stimulate the development of CAI and the formation of a courseware market including courseware design, development, evaluation and diffusion. This has never before occurred in Chinese computer education history. The cooperative group on CAI research and courseware development has been built up to meet the needs of courseware development. Of this research group the authors are the main members from Beijing Normal University (BNU). The research work has put an emphasis on primary mathematics CAI and was approved by SEC in early 1994 . The group has designed and developed a courseware series of elementary mathematics on geometry from 1st to 6th school year. This series has now been prepared for commercial use and has been successfully tested and used in some primary schools in Guang Don, Jiang Su province and Beijing. Some features of the software and advances in design and development are listed below.

Courseware design: The design of the courseware is based on instructional theories as well as cognitive psychology theories and combines the primary school teacher's teaching experience with mathematics teaching methods. This is an advance on previous courseware design in primary and secondary level CAI. Earlier designs were usually based on a teacher's instructional experience which has limitations, although it may have some effect on some occasions. As we know educational technology brings not only media or media application 
into education, but also leads to changes in educational thoughts, ideas and methods as well as in educational organization and management. Teachers want student centred, individualized learning and instruction, but it is difficult to realize this in traditional classroom teaching. Information technology and CAI make it possible, but to realize it we need to do more.

Useful, high quality courseware design should be directed by the theories of instructional design and cognitive psychology, and should take full advantage of computer technology. This is our working principle. The knowledge within the elementary geometry courseware is represented as a multilevel network which is connected according to knowledge relationships and learning order. The links are between nodes at the same and in different levels of knowledge. The highest level nodes are listed from simple to complex as points, lines, angles, areas and volume; the second level nodes (areas for example) are concepts of area, area unit, rectangle, square, parallel quadrilateral shape, triangle, ladder shape, circle, ring, fan, complex areas, etc. This kind of knowledge representation is adaptable to the cognitive learning processes and makes it easier for students to absorb new knowledge into existing knowledge structures by linking to earlier learned knowledge; it also helps learning comprehension and knowledge application.

The courseware design determines the instructional strategy, teaching sequences based on the knowledge representation network, teaching rules and links between nodes of the network, student learning history and types of learning outcome. Teacher's teaching experience and instructional methods are embedded in the instructional design process. For example a common error in square recognition is that students do not consider a square which is shown irregularly, as a square. So the program is designed to change the position gradually by means of rotation and parallel movement to deepen students' concept of the attributes of a square.

To deduce the area calculation formula is usually difficult in traditional teaching and students find this difficult to learn by heart. The software visually demonstrates the process step by step by graphs and animations. This kind of instructional strategy enriches student's images of geometry and image operation so as to deepen their spatial concepts and to build a bridge from concrete perception to abstract thinking. Above all the students really understand what they have learned instead of mechanically memorizing facts and can apply what they have learned in practice. After tutorial and simulation the program gives a number of examples, exercises and tests according to the student's learning history and level, as well as giving feedback and an evaluation of student performance. 
Couseware engineering: Professional programmers and artistic designers work together to realize the instructional design of the courseware. The programs are developed in the high level programming language $\mathrm{C}++$. Graphs, various Chinese character presentation styles, sounds and animations raise pupil interest and keep their attention. The presentation of Chinese characters is effected outside from the Chinese operation system. Graphs and animations are drawn with Paintbrush under Windows 3.1, the interface and the courseware operations are easy and friendly. These courseware developments are effective because these follow the courseware engineering approach and are typical examples of Chinese commercialized courseware development (for both primary and secondary schools) in its current stage of development. The next step of the project is to diffuse the courseware already developed and then to develop elementary mathematics CAI courseware to cover all elements of the curriculum; finally to develop the courseware to take account of trends in Intelligent CAI (ICAI), networking and hypermedia.

\section{CONCLUSION}

For ten years of computer education development the content and form of computer education in Chinese primary and secondary schools have changed a great deal. Among those changes CAI is the main future direction for computer education. Combined with basic education it is an effective means to drive the reform of Chinese education further. CAI activities are being systematically researched and experiments with defined plans, organization and objectives have evolved from scattered and spontaneous experiments. A systematic market mechanism of software design, development, evaluation, diffusion and application has been established step by step. During this practical process CAI theories and related theories have been applied and act as the guide to CAI practice, but also have been prompted by research results and experimental experience.

The aim of the future development of CAI in basic education in China is to enlarge and deepen experimental research, and then to expand the practice of CAI within subjects, instructional content, individual schools and regions. On the other hand new technology experimental research should be strengthened using multimedia, ICAI and communication networks so that we can accelerate and deepen the development of computer education, deepen fundamental educational reform and train qualified citizens for the 21 st century. 


\section{REFERENCES}

1. He Ke Kang (1994) Chinese cognition and Chinese character coding scheme. Beijing Normal University Press.

2. Lin Chong De (1992) Learning and development. Beijing Education Press.

3. Burns, H., Parlett, J.W. and Redfield, C.L. (eds.) (1991) Intelligent tutoring systems: Evolutions in design. Hillsdale NJ: Lawrence Erlbaum.

4. Gagne, R.M., Briggs, L.J. and Wager, W.W. (1988) Principles of instructional design (3rd edn.) New York: Holt, Rinehart and Winston. 